\title{
Perinatal Depression in Minority and Underserved Rural Women
}

\author{
Guo Wei, Frankie D. Powell, \\ Veronica K. Freeman and Leonard D. Holmes \\ University of North Carolina at Pembroke
}

USA

\section{Introduction}

Perinatal depression among ethnic minority women is an understudied area of research. More specifically, prior to conducting interventions among this particular population, an extensive understanding of this knowledge base is necessary. Moreover, we are more aware of the multiple interrelationships between depression and various physical diseases, as well as socio-economic conditions and lifestyles. This chapter will explore that knowledge base and offer suggestions for future studies through an approach of social cognitive theory and the investigation of a well-mixed tri-racial and bi-ethnic sample.

\section{Background}

\subsection{Definition of terms}

Depression occurs across the population and throughout the life span. All women are at risk. The prevalence of perinatal depression is about the same as at other times in a woman's life (O'Hara, 1997). However, the consequences of perinatal depression are more compelling, as perinatal depression affects not only the women but their unborn babies, new babies, young children and the entire family support system.

The signs and symptoms of depression include depressed mood, tearfulness, sleep or appetite disturbances, nervousness or anxiety, irritability, weight gain or loss, loss of interest and pleasure, low energy, loss of concentration, guilt, hopelessness and thoughts of harming one's self or one's infant. Depressive symptoms may range from mild to severe. Severe symptoms often include thoughts of dying or suicide, wanting to flee or get away, being unable to feel love for the unborn baby or infant and having thoughts of hurting or not being able to protect the child.

Perinatal depression encompasses major and minor depressive episodes that occur either during pregnancy or within the first 12 months following delivery. Major depression is a distinct clinical syndrome for which treatment is clearly required (American Psychiatric Association, 2000), whereas the definition and management of minor depression are less clear. 


\subsection{Prevalence of perinatal depression}

Global and national data indicate that depression in the general population has implications for both short-term (episodic) and long-term (chronic) mental health disability. Both can lead to traumatic outcomes for individuals and their families. For example, the World Health Organization (WHO) predicts that by 2020, depression will reach second place in the ranking of disability-adjusted life years (DALYs) calculated for all ages and both sexes. Within the context of the implications of depression as a major worldwide mental health disease, this chapter focuses on the critical impact of perinatal depression among minority and underserved rural women.

A national review by Gaynes et al. (Gaynes et al., 2005) on the prevalence of perinatal depression in the United States concluded that, for major and minor depression, the final combined estimates of point prevalence ranged between 8.5 percent and 11.0 percent at different times during pregnancy and between 6.5 percent and 12.9 percent at different times during the first year postpartum. Still, precise levels of the incidence of perinatal depression appear uncertain. Published estimates of the rates of major and minor depression in the postpartum period range widely - from 5 percent to more than 25 percent of new mothers, depending upon the assessment method, the timing of the assessment and population characteristics (O’Hara \& Swain, 1996; Llewellyn, Stowe \& Nemeroff, 1997; Yonkers et al., 2001).

Studies of prevalence included both white and African American women in samples. However, Native American and Hispanic women have not generally been included, thereby limiting the knowledge of perinatal depression in ethnic minority women. Only a few studies have begun to address this gap. In fact, as pointed out by Gaynes et al., "Prevalence studies need to provide better accountability of the racial and ethnic mix of perinatal depression in the U.S. population, as perinatal depression rates differ among various racial and ethnic groups. The absence of information on nonwhite populations was dramatic," which comprises an interest of this chapter.

\section{Conceptual framework}

\subsection{Definition of the concept}

Defining depression is integral to the discussion of its impact on ethnic minority rural women. Depression is a biological, psychotic or psychosocial disorder often marked by depressed mood, nervousness or anxiety, inactivity, difficulty in thinking and concentration, emotional lability, tearfulness, sleep or appetite disturbance, weight gain or loss, loss of interest and pleasure, low energy, feelings of dejection, sadness and hopelessness, feelings of shame or loss of self, mental illness, feelings of guilt and suicidal tendencies. A history of depression and/or a family history of mood or anxiety disorders are significant risk factors for depression. Particularly during the perinatal period, a mother's desire to flee or get away, inability to feel love for the unborn baby or infant and thoughts of hurting or being unable to protect the infant are especially troubling.

Women bear the burden of responsibility associated with being wives, mothers and caregivers. In many underserved populations, women have considerable mental health needs; however, the conception of mental health in women has been limited as have attempts to protect and 
promote it. The weathering hypothesis (Geronimus, 1992) proposes that the health of African American and Native American women may begin to deteriorate in early adulthood as a physical consequence of cumulative socioeconomic disadvantage. African American and Native American women who are believed to be in poorer health than non-Hispanic white women, have a larger chance than non-Hispanic white women of experiencing poorer birth outcomes; however, they are also more sensitive than non-Hispanic white women to an intervention (such as an adequate perinatal care) that improves maternal health and birth outcomes. Hispanic women, whose health and birth outcomes are "better than expected," are receiving the lowest rates of perinatal care. When the health issues of women have been addressed in these populations, activities have tended to focus on issues associated with reproduction-such as family planning and bearing of children-while the mental health of women has been relatively neglected. Understanding perinatal depression in ethnic minority rural women requires a theoretical lens that helps explain how depression affects these women and their families. Social cognitive theory (SCT) is one such theory.

\subsection{Application/relationship to postpartum depression}

Social cognitive theory provides a framework for understanding, predicting and changing human behavior. The theory identifies human behavior as an interaction of personal factors, behavior and the environment (Bandura, 1977, 1986, 1989, 2001). In the model, the interaction between the person and behavior involves the influences of a person's thoughts and actions. The interaction between the person and the environment involves human beliefs and cognitive competencies that are developed and modified by social influences and structures within the environment. The third interaction, between the environment and behavior, involves a person's behavior determining the aspects of his or her environment, and in turn, their behavior is modified by that environment. In short, the three factors environment, people and behavior - are constantly influencing one another. Behavior is not simply the result of the environment and the person, just as the environment is not simply the result of the person and behavior (Glanz et al., 2002). According to Jones (Jones, 1989), "the fact that behavior varies from situation to situation may not necessarily mean that behavior is controlled by situations but rather that the person is construing the situations differently and thus the same set of stimuli may provoke different responses from different people or from the same person at different times."

The application of this theory involves understanding the interrelationships between personal factors (in the form of cognitive, affective and biological events) and the external environment. Perinetal depression, for example, involves the knowledge a woman has about pregnancy and the clinical matters associated with it-how the woman feels about her pregnancy. It also involves the lived experience of the woman. Women who live in different environments see and respond to those environments through different lenses. Steven Covey has alluded to this concept when, in The 7 Habits of Highly Effective People, he states, "We must look at the lens through which we see the world, as well as the world we see, and that the lens itself shapes how we interpret the world." (Covey, 2004)

\subsection{Specifically applied to ethnic minority women}

According to the National Center for Law and Economic Justice (2010), African Americans, Native Americans and Hispanic Americans are more likely than others to live in poverty or 
deep poverty. This is especially true for racial and ethnic women who are the heads of their household and their families. Viewing, interpreting and responding to a highly impoverished environment might very well be a contributing factor to depression.

The depression status of some postpartum women may have become serious enough (e.g. major depression and minor depression), that treatment and/or intervention is required. On the other hand, for other postpartum women the level of depression is minimal, and these women can be treated by enrolling in education and training programs. A natural question arises: Why do some women experience major or minor depression while others do not? To answer this fundamental question, an appropriate method is to explore the differences between the two groups of women regarding their physical diseases, social factors, mental health aspects, personal behaviors and lifestyles among other environments. Such differences can be captured by using the social cognitive theory, which explains how people acquire and maintain certain behavioral patterns. SCT also provides the basis for intervention strategies (Bandura, 1997). The social cognitive theory is relevant to health communication. In fact, this theory deals with cognitive, emotional aspects and aspects of behavior for understanding behavioral change. The concepts advanced by this theory provide opportunities for new behavioral research in health education, ideas, insights, and understanding for other theoretical areas, such as psychology.

By employing the social cognitive theory and implementing its derived strategies, health professionals can better understand the relationships among pregnant women's personal factors, environment factors and behavior factors. As a result, this approach can greatly improve the access to perinatal women living in rural communities, thus increasing participation and retention in health programs. SCT is useful for establishing a basis on which to build a mutual trust between the health providers and perinatal women.

\section{Overview of studies of postpartum depression: A review of the literature}

A review of recent literature indicates the paucity of research about rural Native American and Hispanic women. This limited research underscores the need for data regarding these underserved populations. This review includes designs, methodology (including screening instruments and their reliability) and intervention and treatment models of perinatal depression. Our review includes publications on the studies of postpartum (and prenatal) depression in the past three decades.

Gaynes et al. concluded that up to 19.2 percent of new mothers may have either major or minor PPD in the first three months after giving birth (Gaynes et al., 2005). They also pointed out that, when discussing prevalence studies for PPD, it is clear that more quantitative research is needed to account for racial and ethnic differences. Longitudinal studies should be conducted to identify periods of peak prevalence over the first 12 months after birth. The limited number of published studies hampers the ability of clinicians to plan for the best times and places to screen and intervene. If the prevalence of this mood disorder peaks after six weeks, then screening programs need to be put into place in clinical settings other than obstetrics, such as family practice and pediatrics.

As such, depression in the general population has been extensively studied by many researchers in the past three decades (Beck, 2008). However, for postpartum depression, 
samples of those studies consisted of primarily white American and African American women, leaving the depressive status of other racial/ethnic groups, e.g., Native and Hispanic Americans, essentially unknown. A main purpose of our previous studies (Baker et al., 2005; Wei et al., 2008) and the present study is to eliminate or reduce such a knowledge gap.

\subsection{Screening tools}

The Edinburgh postnatal depression scale (EPDS) has been widely used in clinical settings to identify possible depressed women after giving birth. Peindl et al. (Peindl et al., 2004) investigated the effectiveness of the EPDS for major depression. The outcome of their study was identification of a recurrence of major depression in the first year postpartum by means of a clinical interview and use of the EPDS. Participants were pregnant women who had experienced a previous episode of postpartum-onset major depression (PPMD) but were well during their index pregnancy. This study was part of a double-blind, randomized clinical trial in which new mothers received nortriptyline or placebo within 24 hours following delivery for the prevention of PPMD. An earlier study regarding the development of the EPDS was given by Cox, Holden and Sagovsky (Cox, Holden \& Sagovsky, 1987).

In additions to EPDS, other depression screening tools have been adopted. Recent research on the accuracy of alternative screening tools has been conducted for the Beck Depression Inventory II (BDI-II), and the Postpartum Depression Screening Scale (PDSS) (Chaudron et al., 2010). These approaches claim to identify major depressive disorder (MDD) or minor depressive disorder (MnDD) among low-income, urban mothers attending well-child care visits during their postpartum year. Large proportions of low-income, urban mothers attending WCC visits experienced MDD or MnDD during the postpartum year. In general, the EPDS, BDI-II, and PDSS are very useful in identifying depression, but scoring may need to be altered to identify depression more accurately among urban, low-income mothers.

For women with major depression alone, specificity for all screeners (the BDI, the PDSS and the EPDS) was relatively high and overlapped substantially. This finding suggests that a positive screen was accurate in identifying major depression; that is, the risk that a screen with one of these instruments would be falsely positive was low. By contrast, sensitivities varied much more. The EPDS and the PDSS appeared to be more sensitive (with estimates ranging from 0.75 to 1.0 at different thresholds) than the BDI instruments (with estimates from 0.32 to 0.68 ), but the wide confidence intervals overlapped nearly completely. Thus, the research findings were not supported, i.e., that the sensitivity estimates using the different tools were different (Gaynes et al., 2005).

\subsection{Screening for risk factors}

According to the American College of Obstetricians and Gynecologists Committee (ACOG Committee), psychosocial screening of all women seeking perinatal evaluation or care should be performed regardless of social status, educational level or race and ethnicity. Because problems may arise during perinatal period that were not present at the initial visit, it is best to perform psychosocial screening at least once in every three months to increase the likelihood of identifying important issues and reducing poor birth outcomes. Screening should include assessment of barriers to care, unstable housing, unintended pregnancy, 
communication barriers, nutrition, tobacco use, substance abuse, depression, safety, intimate partner violence and stress (ACOG Committee, 2006; Dobson \& Dozois, 2008).

To clarify whether screening adults for depression in primary care settings improves recognition, treatment and clinical outcomes, Pignone et al. searched the Medline database for data from 1994 through August 2001. Other relevant articles were located through systematic searches of Medline from 1966 to 1994. Other data was taken from the Cochrane depression, anxiety, and neurosis database; hand searches of bibliographies; and extensive peer reviews. The researchers reviewed randomized trials conducted in primary care settings that examined the effect of screening for depression on identification, treatment or health outcomes, including trials that tested integrated, systematic support for treatment after identification of depression. Meta-analysis suggests that, screening and feedback reduced the risk for persistent depression (summary relative risk, 0.87 [ $95 \% \mathrm{CI}, 0.79$ to 0.95$]$ ). When combined with traditional care, screening for depression can improve outcomes, particularly when screening is coupled with system changes that help ensure adequate treatment and follow-up (Pignone et al., 2002).

\subsection{Among minority and low-income women: Health disparities}

Kozhimannil et al. (2001) investigated racial/ethnic differences in mental health care associated with postpartum depression in a multiethnic cohort of Medicaid recipients. The study included logistic regression for initiation of antidepressant medication or outpatient mental health visits within six months of delivery, follow-up and continued mental health care. There were significant racial/ethnic differences in depression-related mental health care after delivery. Suboptimal treatment was prevalent among all low-income women in the study. However, race- and ethnicity-based disparities in the initiation and continuation of postpartum depression care were particularly troubling and warrant clinical and policy attention. With analyses controlling for clinical factors, the odds of initiating treatment after delivery were significantly lower for African Americans and Hispanics compared with whites. Among those who initiated treatment, African Americans and Hispanics were less likely than whites to receive follow-up treatment or continued care. Among those who initiated antidepressant treatment, African American and Hispanic women were less likely than whites to refill a prescription. There were significant racial-ethnic differences in depression-related mental health care after delivery.

In contrast, for prenatal depression, research was conducted where risk factors for major prenatal depression among African American women were studied (Luke et al., 2009). They determined the prevalence and risk factors for major prenatal depression among lowincome African American women, and used logistic regression to identify risk factors for major prenatal depression. The risk for major prenatal depression increases about five-fold among low-income African American women from age 30 as compared to teen mothers. The results are consistent with the weathering effect that results from years of cumulative stress burden due to socioeconomic marginalization and discrimination. Older African American mothers may benefit from routine prenatal depression screening for early diagnosis and intervention.

Plant and Sachs-Ericsson (Plant \& Sachs-Ericsson, 2004) examined the depressive symptoms and prevalence of major depression among members of ethnic and racial minorities and 
white people from a large random sample. Minority group members experienced more depressive symptoms and a marginally higher prevalence of major depression than did white participants. These effects were mediated by participants' problems meeting their basic needs. Especially, minority group members reported more problems meeting their basic needs, and these problems were associated with an increased risk for depression and depressive symptoms. Interestingly, minority group members also reported a higher quality of interpersonal functioning than white participants did, which appeared to suppress the relationship between ethnicity and depression. However, measuring "interpersonal functioning" may be problematic.

Other quantitative work has explored the relationship between race and depression. Segre, O'Hara and Losch examined the extent to which race/ethnicity is a risk factor for depressed mood in late pregnancy and the early postpartum period, apart from its relationship with other demographic and infant outcome variables (Segre, O'Hara \& Losch, 2006). Compared to white women, African American women were significantly more likely to report depressed mood $(95 \% \mathrm{CI}=1.03-1.52)$; Hispanic women were significantly less likely to report being depressed $(95 \% \mathrm{CI}=0.61-0.88)$. Moreover, authors also explored the role of social support in understanding the above findings.

Zayas, Jankowski and McKee (2005) studied parenting competency in a major life transition occurring within the context of an impoverished urban environment (Zayas, Jankowski \& McKee, 2005). They also explored associations with depression, social support and life events. A sample of 182 African American and Hispanic mothers educated at community health centers in low-income urban areas completed measures early in the third trimester and again at three months postpartum. Across time, the levels of reported parental efficacy and satisfaction increased, while depressive symptoms decreased. Experiences at community health centers positively influenced women's experience of parenting satisfaction and feelings of efficacy before and after their babies were born.

Postpartum depression is prevalent in approximately 10 to $20 \%$ of women in the United States. Studies by Segre and colleagues, suggest that women of low income are at a higher risk of experiencing PPD than their more affluent counterparts, and African American women are more likely to suffer from PPD than both Hispanic and white women (Segre et al., 2006, 2007). Their first study focused on the income, education, marital status, number of children and occupational prestige of 4,332 women who, on average, gave birth 4.6 months prior to the research evaluation. These results indicate that social status is a significant predictor of PPD, with income as the strongest predictor. Their second study examined race and ethnicity as a factor for PPD. Data from the survey revealed that $15.7 \%$ of all women exhibited a single depressive item. African American women were most likely to report a depressive mood, while Hispanic women were least likely to report a depressive mood. Both studies emphasized the need for early PPD identification programs and strong social support for women with newborns.

\subsection{Treatment and interventions}

Appleby et al. (Appleby et al., 1997) studied the effectiveness of fluoxetine and cognitive behavioral counseling. They used a randomized, controlled treatment trial, double-blind in relation to drug treatment, with four treatment cells: fluoxetine or placebo plus one or six 
postnatal sessions of counseling for a sample of 87 women at six to eight postnatal sessions. Seventy percent of the participants completed 12 weeks of treatment. The Edinburgh postnatal depression scale and the Hamilton depression scale were used. Highly significant improvement was seen in all four treatment groups. The improvement in subjects receiving fluoxetine was significantly greater than in those receiving placebo. The improvement after six sessions of counseling was significantly greater than after a single session. Interaction between counseling and fluoxetine was not statistically significant. These differences were evident after one week, and improvement in all groups was complete after four weeks. They concluded that both fluoxetine and cognitive-behavioral counseling given as a course of therapy are effective treatments for nonpsychotic depression in postnatal women. After an initial session of counseling, additional benefit results from either fluoxetine or further counseling but there seems to be no advantage to receiving both.

A pilot study was conducted to examine the initial acceptability, feasibility and effectiveness of the ROSE program (Research, Observation, Service and Education) in the College of Medicine of the University of Cincinnati, using a brief, interpersonally based intervention in a group of low income, rural African American pregnant women at risk for PPD (Crockett et al., 2008). Participants were randomly assigned to the ROSE program or to treatment as usual (TAU). The women in the intervention condition reported significantly better postpartum adjustment at three months postpartum than women in the TAU group. Those in the ROSE program reported improvement in depressive symptoms over time, whereas women in the TAU group did not evidence such changes.

\subsection{Relation to social supports}

Surkan et al. examined the relationship of social support and social networks to symptoms of depression in a multiethnic sample of early postpartum women (Surkan et al., 2006). Univariate statistics assessed the relationship between Center for Epidemiologic Studies of Depression Scale (CES-D score) and each of the independent variables. Multivariate linear regression models included core socio-demographic variables alone, the core model with each of the social support and social network variables added separately, and all variables together. They evaluated interactions between race and social support, race and social networks and social support and social networks. As may be predicted, both social support and social networks were statistically significant and independently related to depressive symptomatology.

\subsection{Recent findings}

Knowledge regarding PPD remains incomplete at present. Despite the current classification of postpartum depression, doctors and clinicians with experience treating depressed mothers often note specific differences between unipolar depression and the depression that occurs immediately after childbirth. Silverman et al. (Silverman et al., 2011) recently used state-of-the-art brain imaging technology, functional magnetic resonance imaging (fMRI), to assess the neuroanatomical responsivity of the amygdala in women six to eight weeks postpartum and to understand how the brains of women with postpartum depression differ from non-depressed postpartum woman. While contemporary diagnostic nosology characterizes postpartum depression (PPD) as a specifier of a major depressive disorder (MDD), this traditional classification continues to be questioned. fMRI holds the promise of 
helping to characterize the neuroanatomical dysfunction associated with dysregulated emotion after childbirth. Postpartum depression (PPD) is nosologically classified as a specifier of a major depressive disorder (MDD); however specific differences in the clinical presentation of PPD have been identified (Cooper et al., 2007).

According to Silverman, depression comes in two types: unipolar and bipolar (see also, Verinder, 2010). Unipolar depression is characterized by severe depression, whereas bipolar type depressions include times of unusually elevated mood or energy - referred to as mania or hypomania. In the DSM-IV, the diagnostic manual used by psychiatrist and psychologists, postpartum depression is classified as a unipolar type depression. The results of the Silverman study suggest this classification might be inaccurate.

\section{Overview of the methodologies used to study postpartum depression}

\subsection{Description of the setting}

The purpose of this study was to examine the relationship between different levels of postpartum depression and the concomitant intervention. The setting of this study was the southeastern section of North Carolina, commonly known as the Sandhills, in Robeson County. Its population is very diverse (U.S. Census 2000): Lumbee Indian (46,896 or 38.0\%; $1.2 \%$ for NC, $0.9 \%$ national), African American (30,973 or $25.1 \%$; $21.6 \%$ for NC, $12.3 \%$ national), white $(40,460$ or $32.8 \%)$ and those of Hispanic origin $(5,994$ or $4.9 \%)$. The Hispanic population is rapidly growing, increased from 704 in 1990 to 5,994 in 2000 (850\% increase). While the county population based on the 2010 census is not available yet, the predicated Hispanic population accounts for approximately 10 percent of the county population. In fact, for 2005 to 2007, Hispanic infants (an average of 385 births per year) accounted for 17.7 percent of all infants in the county (annual average live births 2,177 in 2005-2007). Two previous studies on postpartum depression (Baker et al., 2005; Wei et al., 2008) and a recent analysis of the depression during pregnancy (unpublished) have demonstrated extremely high rates of postpartum depression and prenatal depression in Robeson County.

\subsection{Sample designs}

Postpartum depression in white and African American women has been studied by many researchers (Beck, 1995, 2003; Amankwaa, 2003). The absence of information about other populations is striking (Gaynes et al., 2005). In particular, the depressive status of Native American and Hispanic women is essentially unknown; a direct comparison among African American, Hispanics, Native American, and white women remains a gap in the literature.

Our research addressed such a gap by using data obtained from Robeson County, North Carolina, through our Healthy Start Corps (HSC) project, which has been funded by the Health Resources and Services Administration (HRSA), the U.S. Department of Health and Human Services since 1998. Between September 1, 2002 and January 31, 2006, the HSC project and its clinical partner Robeson Healthcare Corporation (RHCC) recruited 1,245 postpartum clients from Robeson County, North Carolina, for treatment. It should be noted that the women administered Postpartum Depression Screening Scale (PDSS) were not randomly selected for two reasons: 1) the RHCC serves the primarily socio-economically underrepresented population in Robeson County; 2) the policies for this project require 
services be provided primarily to low income Native American and African American women. As a result, approximately $52 \%$ (645) of the 1,245 postpartum clients received the PDSS screenings at the six-weeks postpartum, with subsequent clinical referral as warranted. However, because of the timelines of reports, data analysis was conducted two times: 586 women (for disparities in PPD) and all the 645 women (for effectiveness of treatment and interventions on PPD), respectively.

The population studied is comprised of high-risk women who reflect the ethnic, social and cultural composition of Robeson County. The study group includes Healthy Start eligible women in Robeson County, North Carolina that initially visit the county health department and meet at least three of the following criteria for admission into Healthy Start: inadequate housing, relationship problems, adolescent mother, STD/HIV, poor pregnancy outcomes, spousal abuse/neglect, tobacco/alcohol/drug use or abuse, conflict/violence in the home, no perinatal care, missed appointment, illiteracy, financial problem, cultural/racial disparity, poor nutrition and/or history of depression.

The project's scope covered home-based preconceptional health through postpartum and interconceptional phases for high-risk mothers and infants. HSC cooperates with RHCC (2002 to 2006), Robeson County Health Department (since 2006) and other providers to deliver perinatal services for high-risk prenatal, postpartum and interconceptional women as well as infants. Perinatal health assessment, risk factors and depression screens aligned with continuous counseling and goal setting resulted in better birth outcomes, healthier behaviors, reduced risks and improved self-esteem of clients.

To achieve representative samples of participants, stratified and tree classification, and Bayesian methods were employed (Kadane, 1996). Table 1 summarizes the racial/ethnic distributions of the sample, along with comparisons to the racial/ethnic distributions of relevant populations (U.S. Census 2000). Native American and Hispanic women were oversampled; white women were undersampled.

\begin{tabular}{|c|c|c|c|c|c|}
\hline \multirow{2}{*}{ Group } & \multicolumn{2}{|c|}{ Sample } & \multirow{2}{*}{$\begin{array}{c}\text { Robeson County } \\
(\%)\end{array}$} & \multirow{2}{*}{$\begin{array}{c}\text { North } \\
\text { Carolina (\%) }\end{array}$} & \multirow{2}{*}{ USA $(\%)$} \\
\hline & No. & $\%$ & & & \\
\hline $\begin{array}{l}\text { Non-Hispanic } \\
\text { Native }\end{array}$ & 305 & $52.00 \%$ & $\begin{array}{c}37.7 \% \\
\text { (Lumbee Tribe) }\end{array}$ & $1.20 \%$ & $0.70 \%$ \\
\hline $\begin{array}{l}\text { Non-Hispanic } \\
\text { African }\end{array}$ & 142 & $24.20 \%$ & $25.00 \%$ & $21.40 \%$ & $12.10 \%$ \\
\hline $\begin{array}{l}\text { Non-Hispanic } \\
\text { White }\end{array}$ & 51 & $8.70 \%$ & $30.80 \%$ & $70.20 \%$ & $69.10 \%$ \\
\hline Hispanic & 81 & $13.80 \%$ & $4.90 \%$ & $4.70 \%$ & $12.50 \%$ \\
\hline Other* & 7 & $1.20 \%$ & $1.60 \%$ & $2.50 \%$ & $5.60 \%$ \\
\hline Total & 586 & $100 \%$ & $100 \%$ & $100 \%$ & $100 \%$ \\
\hline
\end{tabular}

* Non-Hispanic individuals of other races and non-Hispanic individuals of two or more races.

Table 1. Racial-ethnic distributions of the sample and population

The goal of this research was two-fold: 1) to estimate the prevalence of postpartum depression for African American, Hispanic, Native American, and white women and determine any presence of racial or ethnic differences and disparities; and 2) to integrate 
research findings and work in concert with the case management teams for the design of more targeted and feasible admission procedures and more effective intervention strategies and treatment plans. The first analysis included 586 of the 645 women, and the main purpose was to study racial/ethnic disparities (Wei et al., 2008). The second analysis included all the 645 women, and the main purpose was to investigate the effectiveness of the program interventions and treatment plans, based on the comparison of the initial screening results with follow-up screening results. The PDSS screenings were administered by the team supervisor, nurses, social workers, outreach workers and case managers trained in data collection and handling client confidential information.

\subsection{Screening tool: Postpartum Depression Screening Scale (PDSS)}

The PDSS is a self-report instrument with 35 items measuring depression and 10 for demographic characteristics. The 35 items are also grouped into seven symptom subscales: sleeping or eating disturbances, anxiety/insecurity, emotional lability, mental confusion, loss of self, guilt/shame and suicidal thoughts. If the score for the first seven items (short score) is less than 14, a full screening is not administered, and the client is classified as Normal Adjustment. If a score of 14 or higher is identified, the client completes the remaining 28 items in the same day. If the full score is between 60 and 79 , the client is classified as Minor Depression; if 80 or higher, the client is classified as Major Depression. In either case, the client is referred for appropriate intervention or treatment.

\subsection{Data analysis methods and software tools}

To explore risk factors of depression, the factor analysis method was first used to extract the characteristics of these women. The assumptions required include no outlier, adequate sample size, linearity, no perfect multicollinearity and linear data. Factor analysis is a statistical method by which the regularity and order in phenomena can be discerned. It is a detection method for data structure, but it is different from principal component analysis whose purpose is data deduction (Hair et al., 1992; Dillon \& Goldstein, 1984). Factor analysis is used to investigate interdependencies between variables in an effort to explore a new set of variables (fewer in number than the original set of variables), which express commonality among the original variables. The essence of factor analysis is to simplify complex and diverse relationships that exist among the set of observed variables by uncovering common dimensions or factors that link together the seemingly unrelated variables. Another method used was the structural equation models approach that allows both confirmatory and exploratory modeling and is suited to both theory testing and theory development.

Four different approaches for assessing reliability analysis were considered for the reliability of the instruments measuring the tri-racial and bi-ethnic population: test-retest reliability, internal consistency reliability, split half reliability and inter-rater reliability. Confidence intervals of the rates of major and minor depression by group were estimated (Table 2), followed by statistical tests to first determine the differences among these rates and then explore the differences in variations of full scores and differences in mean full scores 
between groups. Risk assessment was performed with factor analysis and correlation methods (Wei et al., 2008).

\begin{tabular}{|c|c|c|c|c|c|c|c|c|c|c|c|c|c|c|}
\hline \multirow{3}{*}{$\begin{array}{l}\text { Racial } \\
\text { or } \\
\text { Ethnic } \\
\text { Group }\end{array}$} & \multirow{2}{*}{\multicolumn{5}{|c|}{$\begin{array}{c}\text { PDSS Short Scale } \\
\text { (Total score of first seven items) }\end{array}$}} & \multicolumn{9}{|c|}{$\begin{array}{c}\text { PDSS Full Scale } \\
\text { (Total score of all thirty five items) }\end{array}$} \\
\hline & & & & & & \multicolumn{5}{|c|}{$\begin{array}{l}\text { Major Depression } \\
(\% \text { in all } 586 \text { women })\end{array}$} & \multicolumn{4}{|c|}{$\begin{array}{l}\text { Minor Depression } \\
(\% \text { in all } 586 \text { women })\end{array}$} \\
\hline & No & $\geq 14$ & $\%$ & $\begin{array}{c}\text { Lower } \\
95 \% \\
\text { CI }\end{array}$ & \begin{tabular}{|c} 
Upper \\
$95 \%$ \\
CI
\end{tabular} & No & $\geq 80$ & $\%$ & \begin{tabular}{|c|} 
Lower \\
$95 \%$ \\
CI
\end{tabular} & \begin{tabular}{|c} 
Upper \\
$95 \%$ \\
CI
\end{tabular} & $60-79 \mid$ & $\%$ & \begin{tabular}{|c|} 
Lower \\
$95 \%$ \\
CI
\end{tabular} & $\begin{array}{l}\text { Upper } \\
95 \% \\
\text { CI }\end{array}$ \\
\hline White & 51 & 23 & 1 & 31. & 58.8 & 24 & 9 & 17.6 & 7.2 & 28.1 & 10 & 19.6 & 8.7 & 30.5 \\
\hline African & 142 & 47 & 33.1 & 25.4 & 40.8 & 48 & 21 & 14.8 & 9.0 & 20.6 & 14 & 9.9 & 5.0 & 14.8 \\
\hline Native & 305 & 126 & 41.3 & 35.8 & 46.8 & 128 & 57 & 18.7 & 14.3 & 23.1 & 32 & 10.5 & 7.1 & 13.9 \\
\hline Hispanic $^{1}$ & 81 & 5 & 6.2 & 0.95 & 11.5 & 4 & 2 & 2.5 & -0.9 & 5.9 & 0 & 0.0 & 0.0 & 0.0 \\
\hline Other & 6 & 2 & 33.3 & -4.4 & 71 & 4 & 1 & 16.7 & -13.1 & 46.5 & 1 & 16.7 & -13.1 & 46.5 \\
\hline Total & 586 & 203 & 34.6 & 30.7 & 38.5 & 209 & 90 & 15.4 & 12.5 & 18.3 & 58 & 9.9 & 7.5 & 12.3 \\
\hline
\end{tabular}

${ }^{1}$ Hispanic women are not included in the racial groups.

Table 2. Racial and Ethnic Prevalence of Postpartum Depression

The major factors (and their components - original 35 factors in the PDSS holding loadings larger than 0.70; factor loadings less than 0.40 dropped; standard regression coefficients used) were identified according to the order of significance where italic (component) factors had average ratings of "agree" or "strongly agree" from the 90 likely major depressive participants. The Henry Kaiser's eigenvalue-based rule (Rule of Thumb) was used: The total number of factors is chosen as the number of eigenvalues of the correlation matrix that are larger than one (Morrison, 1990). The software tools used included SAS and SPSS. The significant first seven items are:

1. Mental confusion (moving or pacing, anxiety, difficulty focusing on task, hard to make decisions, anger, crazy, irritable),

2. Suicidal thoughts (better off dead, seemed death, want to hurt self, want to leave the world, not normal),

3. Trouble sleeping and imaginary feeling (feeling not real, trouble sleeping, stranger to self, hard back sleep, tossed and turned to sleep, jump out of skin, feel alone),

4. Guilt or shame (not loving baby, felt baby better without me, felt failure as mother, hide thinking and feeling, not mother wanted to be, felt others better),

5. Loss of self (felt never be normal, lost mind, never happy),

6. Emotional lability (overwhelmed, roller emotion) and

7. Eating disturbance (should but not eat, lost appetite).

\subsection{Racial differences and ethnic disparities (586 women)}

Three racial groups (African American, Native and white) shared similar depression status. Major dissimilarities existed between the Hispanic group and the non-Hispanic group (Wei et al., 2008). The prevalence of depression at six weeks postpartum in a rural triracial population using the Beck and Gable PDSS found that Native American women had the highest rate of major depression (18.7\%) and average rates of minor depression $(10.5 \%)$. Although white women had the second highest rate of major depression $(17.6 \%)$ and the 
highest rate of minor depression (19.6\%), their average full score (76.1) was still significantly lower than that of Native American women (82.9) (at $\alpha=0.23)$ and slightly lower than that of African American women (78.9, major depression 14.8\%). Hispanic women had the lowest rates of major and minor depression (2.5\%) (Table 2).

\section{Early intervention study - identification, intervention and treatment}

This data supports the hypothesis that timing and quality of perinatal care received by the mother during pregnancy and in the postpartum period are critically important to both the mother and the infant. Early comprehensive perinatal care can promote improved perinatal health by providing health behavior advice, monitoring, early detection and treatment of risk factors and symptoms.

\subsection{Screening with clinical setting}

Healthy Start Corps (HSC) operates on the principle that prenatal counseling or early postpartum screening for depressive symptoms with subsequent intervention will lead to improved health outcomes for the mother and her infant. The postpartum clients in the program were all given at least one initial depression screening at six weeks postpartum, with possible screening results ranging within normal adjustment, significant symptoms of (minor) postpartum depression, or major postpartum depression. Women identified as atrisk for major and minor depression were given subsequent screenings in the fourth month and twelfth month after delivery. Literature on postpartum depression was distributed to all participants. All participants were provided one-on-one counseling and education regarding the differences between baby blues, postpartum depression and postpartum psychosis, signs and symptoms of depression, high risk factors for postpartum depression and the significance of public health concerns of postpartum depression.

As a participant of HSC, weekly home visits occurred until the client exhibited a stable mental and emotional status. Follow-up was made regarding mental health appointments and medication regimen effectiveness. Increased rest and support from family and friends were encouraged for childcare and chores in promoting optimal mental and emotional wellbeing. Participants were encouraged to engage in activities to promote increased socialization among other participants who had experienced many of the same postpartum depression episodes through group activities arranged by the HSC.

Because of religions, beliefs, traditions, lifestyles and desire for privacy and other reasons, it is a challenge for health professionals to access local communities and organizations and recruit program participants. This effort is especially difficult when recruiting for community-based programs, such as the U.S. National Healthy Start programs, which has been funded by the Health Resources and Services Administration of the U.S. Department of Health and Human Services since 1991. These programs focus on reducing infant mortality and eliminating health disparities by promoting adequate perinatal care for minority and underserved women. Efficient and experienced case managers could be placed into embarrassing situations when delivering home-based perinatal services, e.g. depression screens, as experienced by Healthy Start's interconceptional case management programs. 


\subsection{Interventions}

Interventions Used for Normal Postpartum Participants (PDSS Short Score $\leq 13$ or Full Score $\leq 59$ ): Soon after giving birth (during the postnatal period), most new mothers experience mood swings and mild depression (baby blues). This condition usually peaks from a few days day after delivery to the end of the second week. Afterwards (during the postpartum period), for a majority of women, their bodies enter a normal adjustment category in response to changing postpartum hormone levels. One method of active prevention that was helpful for the HSC postpartum women was a brief intervention, derived from the principles of social learning theory and empirically validated as an effective methodology. These participants received the HSC- distributed literature on postpartum depression, were recommended to attend the HSC health education classes, were encouraged to get plenty of rest and elicit the support of family and friends for childcare and chores and were offered Healthy Start and Child Service Coordination as an additional source of support.

Methods of Treatment Used for Participants with Significant Symptoms of (Minor) Postpartum Depression (PDSS Full Score 60-79): One-on-one counseling was often provided by an HSC-trained social worker within the home for each woman, and a referral to a mental health agency was offered. These participants were educated on postpartum depression and were given additional literature on postpartum depression, including emergency contact numbers. These participants were also offered HSC health education classes and Child Service Coordination. A home visit was made weekly up until the eighth week postpartum for each woman by the maternity care coordinator (MCC) in order to evaluate her emotional status as well as the interaction with her infant. Again substantial rest and the support of family and friends for child care and chores were encouraged for optimal emotional well being. Screening occurred at varying times since postpartum mood disorders could be expressed in a variety of ways and at different time intervals. The HSC postpartum and interconceptional case management teams continued to use the PDSS tool to monitor all postpartum and interconceptional clients. All clients are provided one-on-one counseling on the differences between baby blues and postpartum depression/psychosis, the signs and symptoms of depression, high risk factors for postpartum depression, the public health concerns of postpartum depression and the role and approaches in providing information to the community on the signs and symptoms of postpartum depression.

Methods of Treatment Used for Participants with Major Postpartum Depression (PDSS Full Score $\geq 80$ ): If depressive and psychiatric symptoms were first encountered within the clinical setting and a major postpartum depression screening was identified, a same day referral to a clinical physician was made. Further referrals were then made with an outside provider if psychiatric counseling was required, dependent upon the severity of conditions. Additionally counseling sessions were arranged by HSC with a local provider for up to four visits with costs being absorbed by HSC. Follow-up by HSC was carried out by verifying that participants kept appointments with the care provider and by rescheduling referral appointments as needed. Participants who had scores indicative of major depression were encouraged not to leave the facility without seeing a medical provider (MD, PA, or NP). The medical provider proceeded in extensive education with the participant regarding the postpartum depression screening results and encouraged the acceptance of a referral to a 
mental health professional. Antidepressant medications were usually prescribed by the medical provider. If there was concern regarding suicidal ideation or a threat of potential harm to others, the participant was referred for emergency services and immediate evaluation. Consent was sought for confiding in the spouse or significant others for education on the dangers of untreated major postpartum depression and intervention options. Again literature was given to the couple including emergency contact phone numbers (hospital, mental health agency, etc). HSC referrals and Child Service Coordination services were offered as well. The maternal care coordinator contacted the high-risk participant every other day for several days and made a home visit weekly up until eight weeks postpartum.

\subsection{Initial screening results}

The initial screening was administered at the sixth week postpartum to all the 645 women. Women in the whole sample showed similarities and dissimilarities by racial/ethnic group. These group averages are close for age, history of depression, treatment history, gravida, number of children, delivery method and low family income. Major differences included that Hispanic women had a lower education level than non-Hispanic women, but the highest breast feeding rate; white women had the highest percentage of marriages, while African American women had the lowest marriage percentage.

\begin{tabular}{|c|c|c|c|c|c|c|c|c|}
\hline & \multicolumn{3}{|c|}{ PDSS Short Scale } & \multicolumn{5}{|c|}{ PDSS Full Scale } \\
\hline & \multirow{2}{*}{\multicolumn{3}{|c|}{ Significant Symptoms }} & & \multirow{2}{*}{\multicolumn{2}{|c|}{$\begin{array}{c}\text { Major } \\
\text { Depression } \\
\text { (\% in all } 645 \\
\text { women) }\end{array}$}} & \multirow{2}{*}{\multicolumn{2}{|c|}{$\begin{array}{c}\text { Minor } \\
\text { Depression } \\
\text { (\% in all } 645 \\
\text { women) }\end{array}$}} \\
\hline & & & & & & & & \\
\hline Race & No. & $\geq 14$ & $\%$ & No. & $\geq 80$ & $\%$ & $60-79$ & $\%$ \\
\hline White & 55 & 25 & 45.5 & 26 & 10 & 18.2 & 11 & 20 \\
\hline $\begin{array}{l}\text { African } \\
\text { American }\end{array}$ & 157 & 49 & 31.2 & 50 & 21 & 13.4 & 16 & 10.2 \\
\hline Native & 338 & 138 & 40.8 & 139 & 62 & 18.3 & 34 & 10.1 \\
\hline Hispanic & 87 & 6 & 6.9 & 5 & 2 & 2.3 & 1 & 1.1 \\
\hline Other & 8 & 3 & 37.5 & 5 & 1 & 12.5 & 2 & 25 \\
\hline Total & 645 & 221 & 34.3 & 225 & 96 & 14.9 & 64 & 9.9 \\
\hline
\end{tabular}

Table 3. Racial and Ethnic Disparities - Initial Screening

Table 3 summarizes the racial and ethnic disparities based on the PDSS short scale for the 645 women and the PDSS full scale for the 225 women who were required to take the full screen. The full scale screening determined 96 had major postpartum depression, and 64 had significant symptoms (minor depression). Note the percentages in all the tables are calculated on the basis of the original sample ( 645 postpartum women). The first column from left under PDSS full scale indicates the numbers of women who completed the full scale screening in relevant categories, respectively. With direct calculations from Table 3, the incidence of major and minor postpartum depression in the 645 women was $(96+64) / 645=24.8$ percent. The results support previous racial data: Native women had the highest incidence of major postpartum depression $(18.3 \%)$, followed by white women 
(18.2\%), African American women (13.4\%), and finally Hispanic women (2.0\%). White women were most likely to have minor postpartum depression $(20.0 \%)$, followed by African American women (10.2\%), Native American women (10.1) and finally Hispanic women $(1.1 \%)$.

\subsection{Depressive status of the postpartum women (follow-up screenings after intervention and treatment)}

The follow-up PDSS full screening was conducted at the end of the fourth month after delivery for all women whose PDSS scores at the six-week postpartum were higher or equal to 60 (major or minor depression). Table 4 below shows the results, compared to Table 3 of the initial screening. This indicates a significant improvement for all racial/ethnic groups. Of the $160(96+64)$ women who had major and minor depression (Table 3), 137 received the second screening (Table 4). For all women, the rate of major depression was reduced from $14.9 \%$ at six weeks postpartum to $3.7 \%$ (white: $18.2 \%$ to $1.8 \%$; African American: $13.4 \%$ to $3.8 \%$; Native American: $18.3 \%$ to $4.7 \%$; Hispanic descent: $2.3 \%$ to $1.1 \%$ ). For all women, the rate of minor depression dropped from 9.9 percent at six weeks postpartum to $4.0 \%$ (white: $20.0 \%$ to $5.5 \%$; African American: $10.2 \%$ to $4.5 \%$; Native American: $10.1 \%$ to $4.4 \%$; Hispanic descent: $1.1 \%$ to $0.0 \%$ ). The combined major and minor depression rate was reduced from $24.8 \%$ at six weeks postpartum, which is high compared to various estimates in other populations (Gaynes et al., 2005), to a level of $7.7 \%$, which is close to the midrange of other populations. Hence, the outcomes from the interventions and treatments were significant. (If the sample size was larger, participants could be divided into a treatment group and a control group to admit a direct comparison.)

\begin{tabular}{|c|c|c|c|c|c|c|}
\hline & \multirow{3}{*}{\multicolumn{2}{|c|}{$\begin{array}{c}\text { PDSS Short Scale } \\
\text { Significant } \\
\text { Symptoms }\end{array}$}} & \multicolumn{4}{|c|}{ PDSS Full Scale } \\
\hline & & & \multirow{2}{*}{\multicolumn{2}{|c|}{$\begin{array}{c}\text { Major Depression } \\
\begin{array}{c}(\% \text { in all } 645 \\
\text { women })\end{array}\end{array}$}} & \multirow{2}{*}{\multicolumn{2}{|c|}{$\begin{array}{c}\text { Minor Depression } \\
\begin{array}{c}(\% \text { in all } 645 \\
\text { women })\end{array}\end{array}$}} \\
\hline & & & & & & \\
\hline Race & No. & & $\geq 80$ & $\%$ & $60-79$ & $\%$ \\
\hline White & 55 & & 1 & 1.8 & 3 & 5.5 \\
\hline $\begin{array}{l}\text { African } \\
\text { American }\end{array}$ & 157 & & 6 & 3.8 & 7 & 4.5 \\
\hline Native & 338 & & 16 & 4.7 & 15 & 4.4 \\
\hline Hispanic & 87 & & 1 & 1.1 & 0 & 0 \\
\hline Other & 8 & & 0 & 0 & 1 & 12.5 \\
\hline Total & 645 & & 24 & 3.7 & 26 & 4 \\
\hline
\end{tabular}

Note: Percentages are calculated using the basis of all 645 women to allow a comparison with Table 3 .

Table 4. Improved Outcomes - Second PDSS Full Screening

Since 2006 the Healthy Start Corps program has added several supplemental questions to the PDSS regarding participants' demographic information, such as family income, employment status, education level and maternal smoking, and a total of 456 postpartum women were administered the PDSS and the supplemental questions. Of these participants, 161 smoked during postpartum period, 284 did not smoke, and 11 had an unknown status. Thirty-seven $(23 \%)$ of the smokers received scores larger than or equal to 80 (major 
depression), and only $25(8.8 \%)$ received scores larger than or equal to 80 . Levels of depression are also associated with employment status and family income; $5.8 \%$ of full-time workers received a score 80 or higher, while $12.1 \%$ of part-time workers scored 80 or higher, and $15.2 \%$ of unemployed participants received a score 80 or higher. Moreover, the project also screened for prenatal depression since 2006.

\section{Discussion and conclusions}

Postpartum depression (PPD) is an issue critical to the health of women and their infants, as depressive episodes can become chronic or recurrent and lead to substantial impairments in the ability of an individual to handle daily responsibilities. In addition to the seriousness for the postpartum women, it is known that the period immediately following birth is a critical time for the newborn's development; postpartum depression can constitute a serious threat to the infant's well-being.

Major perinatal depression is considerably underdiagnosed, and many women with such symptoms live untreated. Therefore, mothers and their family members may suffer serious adverse effects, that could impact the emotional and psychological development of the child. A simple screening instrument like the PDSS, the PDIS, the BDI or BDI II (Gaynes et al., 2005) can increase the detection of major depression.

\subsection{Cultural sensitivity and linguistic needs}

Many barriers exist in raising awareness of and intervention of perinatal depression, including stigmatism, denial, transportation, childcare, access to care and, in some cases, lack of insurance when Medicaid is not an option. Health programs may strive to address these barriers in serving high-risk women by forming linkages with community providers and organizations that provide wide services and enrichment activities.

In addition to improving the delivery of treatment and intervention, providers of health programs must reduce cultural and linguistic barriers to perinatal services and support in rural and population-diverse communities. To achieve this goal, health programs and care providers should direct attention to cultural awareness, languages, easy-to-read materials, knowledge and skills, promotion of cultural and linguistic competence, attitudes, legally binding documents, and policies to enable effective cross-cultural working relationships. Family-driven and community-based outreach, flexible appointment times, home visits, and use of cultural brokers and traditional healers are possible approaches. Research and action staff must receive appropriate training to help assess clients' social, emotional and behavioral disorders or mental illness.

Native women are more likely to have inadequate health care, poor nutrition, high adolescent pregnancy rates, high incidences of living in sub-standard housing and, by far, the highest percentage of smoking tobacco during pregnancy. African Americans experience infant mortality and low birth weight rates double that of whites and suffer from nearly all major health causes because they often receive less and poorer quality health care. Hispanic women are generally in poorer health, although some of their health 
indicators are "better than expected," e.g., perinatal depression (known as an epidemiological paradox or the Hispanic paradox), or comparable to that of non-Hispanic white (i.e., infant mortality and low birthweight rates). Hispanic women have been found to initiate childbearing earlier and more likely to give birth to four or more children. Hispanic mothers continue to have children later in life than other women and receive inadequate health care.

\subsection{Challenges - access to care and cultural influences}

In 2010 a focus group study was conducted aimed at uncovering the reasons behind women's refusals and dropouts of various federal, state and community health programs. The focus group interviews and qualitative analysis uncovered several new concepts that contribute to health disparities. Several of the concepts relate directly to cultural and social practices common in Robeson County as well as other factors and barriers. Others relate to issues of trust and poverty. These concepts and the grounded theory method together can provide a basis for instrument developments in future (e.g., survey questionnaires) that can be implemented for the detection of refusals and dropouts from heath programs. Qualitative and quantitative analyses of focus group data and Healthy Start Corps data indicated that issues of trust play a role in healthcare. Subjects do not believe: 1) doctors have their best interests at heart, 2) doctors have up-to-date skill sets or equipment, 3) they will receive adequate care in the hospital or emergency room, and 4) medical personnel will not use race and class as a factor in determining treatments.

Most subjects commented on the role their culture plays in their diets, with many suggesting that a southern diet is filled with fried foods and sugar. One subject phrased it as, "We southerners like a little tea with our sugar and fried chicken." Some claimed that it was a combination of the southern culture and the Native American and African American poverty that led to "eating what you had." Several Native Americans said that their "typical diet" growing up was a breakfast of lard biscuits dipped into a mixture of bacon grease and sugar, a lunch of fatback and vegetables and a dinner of fatback or other cuts of pork and vegetables.

Cost of medical care is a great concern to all subjects regardless of employment and insurance status. Many of the subjects have been unemployed for several years; many have been without insurance for as many as 10 years. One pregnant woman who does have insurance claimed she skips appointments because she cannot afford the co-pays. Focus group participants also talked about alternative strategies, such as borrowing medicines from others who are insured or on Medicaid, using extra medicine around the house, going to the horse feed store or veterinarian to buy animal medicine to treat themselves and home remedies (some scientifically based; others mostly superstition).

\subsection{Advantages and limitations of the study}

The sample is a well-mixed tri-racial and bi-ethnic one, including Native Americans and Hispanic Americans. Using social cognitive theory in the study of depression opens a new door for examining perinatal and mental health. The classification of postpartum women into three categories according to severity of depression is an effective way to deliver 
appropriate and timely interventions and treatments. Moreover statistical methods, including risk factor analysis, are also a significant part of the study.

Limitations of this research include: 1) lack of information about diagnosed major and minor postpartum depression (thus a comparison between the PDSS screening results and actual depression cannot be compared), 2) lack of additional participant health risk information such as prenatal health and substance use and 3) although the original sample size for Hispanic women was not small, the number of Hispanic women who were required to complete PDSS full screening was inadequate.

\subsection{Conclusions}

Fundamental principles of human development attest to three interrelated processes that continue throughout the lifespan on an individual: biological and physical development and health; cognitive development; and socio-emotional development (Santrock, 2008). In addition, the individual is influenced by the social context of these developmental processes. Perinatal depression is both an expression of the link between and the interaction of these three processes within the context of the particular environment. Thus, it is impossible to extricate the findings of this study from the context in which the clients lived. The context included, but was not limited to, conditions of economic underdevelopment and comorbid health conditions, e.g., substance abuse, physical and sexual abuse, diabetes and obesity.

It is within the particular context of these ethnic minority rural women that early identification of postpartum depressive women with subsequent intervention and treatment was found to improve outcomes. The combined rate of major and minor depression was reduced from $24.8 \%$ (at six weeks postpartum), which is high compared to various estimates in literature for other populations (Gaynes et al., 2005; Cox \& Murray, 1993; O'Hara \& Swain, 1996; Llewellyn, Stowe \& Nemeroff, 1997; Yonker et al., 2001), to a level of 7.7\% (in the fourth month after delivery), which is close to the midrange of other populations. The classification of participants into the three categories based on their PDSS scores makes it possible to provide interventions and treatments at the appropriate levels.

Appropriate depression screening can improve health outcomes when combined with a system for treatment. Screening is an effective and feasible strategy in timely identification of depressive women. The Beck and Gable PDSS provided a clinically useful and costeffective (compared with the clinical diagnosing process) screening instrument for early identification of depressive episodes. Depression is treatable and may not be resolved without treatment. Early identification and treatment by primary care clinicians or mental health specialists are essential.

\subsection{Future research}

Refusal of or dropping out of perinatal health services, including critical depression and other risk screen programs, are not uncommon, and these issues are more serious for some racial/ethnic groups (e.g., non-Hispanic African Americans and Native Americans). High refusal and dropout rates of underserved and minority women demonstrate the existence of 
significant gaps between services offered by the current perinatal care system and suitable perinatal care according to the perinatal women themselves. Perinatal women are not likely to accept an offer that does not fit their health needs, judged by their own point of view. To resolve this controversial situation, perinatal care plans and other interventions need to be "redesigned" by incorporating perinatal women's health needs and their view toward health programs. To understand their view, it is clearly necessary for health professionals to study the three factors-personal issues, environmental considerations, and behavioral aspects - of the women.

The social cognitive theory explains how people acquire and maintain certain behavioral patterns, while also providing the basis for intervention strategies (Bandura, 1997). Here, the "patterns" and "basis" as well as the relationships among the above three factors are critically useful information for designing and implementing more effective health programs. According to Levinson, the transition from late adolescence to early adulthood is characterized by the establishment of independence from parents, the exploration of establishing an adult identity, and the formation of life goals (Levinson, 1996). Thus, it is understandable that both the pregnancy and the context of the pregnancy influence the expectant mothers' view of independence, identity, and long-term goals. Her multi-layered socio-cognitive and socio-emotional response is inextricably linked to her depression or her lack of depression. Therefore, further study and wider utilization of this theory and the principles of human development are important, practical, and useful topics for future studies of perinatal depression. Moreover, the inclusion of studies that examine perinatal women's health through an exploration of the female reproductive life cycle from an evolutionary perspective may also be helpful in understanding this topic (Trevathan, 2010). Ultimately, we believe that a decrease in perinatal depression will occur through the elimination of perinatal risk factors, changing of risky behaviors and lifestyles, promotion of cultural and linguistic competence, and the reduction of racial/ethnic disparities.

\section{Acknowledgments}

This work was approved and supported by The University of North Carolina at Pembroke and the Healthy Start Corps project "Eliminating Disparities in Perinatal Health." The Healthy Start Corps project has been funded by the Maternal and Child Health Bureau, Health Resources and Services Administration, U.S. Department of Health and Human Services (Grant Number: H49MC00068) since 1998. This work is also supported by the Sartorius-Stedim Biotechnology Research Laboratory at The University of North Carolina at Pembroke, through an Extramural Associates Research Development Award (EARDA) from the National Institute of Child Health and Human Development (NICHD). Perinatal data analyzed in this work was from the Healthy Start Corps project's database. The annotated bibliography was wellachieved through the efforts of Mr. Dingyang Wei, who is currently a student in the Department of Mathematics at The University of North Carolina at Chapel Hill.

\section{References}

Amankwaa, L. C. (2003). Postpartum Depression among African-American Women. Issues Ment Nurs, Vol. 24, No. 3, (April-May 2003), pp. 297-316, ISSN 0161-2840 
American College of Obstetricinas and Gynecologists (ACOG). (2006). Committee Opinion No. 343: Psychosocial Risk Factors: Perinatal Screening and Intervention. Obstet Gynecol, Vol. 108, No. 2, (August 2006), pp. 469-77, ISSN 0029-7844

American Psychiatric Association (APA). (2000). Practice Guideline for the Treatment of Patients with Major Depression (revision). Am J Psychiatry, Vol. 157, No. 4 Suppl, (April 2000), pp. 1-45, ISSN 0002-953X

Appleby, L., Warner, R., Whitton, A. \& Faragher, B. (1997). A Controlled Study of Fluoxetine and Cognitive-behavioural Counselling in the Treatment of Postnatal Depression. BMJ, Vol. 314, No. 7085, (March 1997), pp. 932-936, ISSN 2044-6055

Baker, L., Cross, S., Greaver, L., Wei, G. \& Lewis, R. (2005). Prevalence of Postpartum Depression in a Native American Population. Matern \& Child Health J, Vol. 9, No. 1, (March 2005), pp 21-25, ISSN 1092-7875

Bandura, A. (1977). Social Learning Theory. Prentice-Hall, ISBN 978-013-8167-44-8, Englewood Cliffs, NJ, USA

Bandura, A. (1986). Social Foundations of Thought and Action: A Social Cognitive Theory. Prentice-Hall, ISBN 978-013-8156-14-5, Englewood Cliffs, NJ, USA

Bandura, A. (1989). Human Agency in Social Cognitive Theory. Amer. Psychologist, Vol. 44, No. 9, (September 1989), pp. 1175-1184, ISSN 0003-066X

Bandura, A. (1997). Self-efficacy: The Exercise of Control, W.H. Freeman, ISBN 978-071-6726-265, New York, NY, USA

Bandura, A. (2001). Social Cognitive Theory: An Agentic Perspective. Annual Review of Psychology, Vol. 52, No. 1, (February 2001), pp. 1-26, ISSN 0066-4308

Beck, C. T. (1995). The Effects of Postpartum Depression on Maternal-infant Interaction. Nurs Res, Vol. 44, No. 5, (September-October 1995), pp. 298-304, ISSN 0029-6562

Beck, C.T. \& Gable R.K. (2002). Postpartum Depression Screening Scale, Western Psychological Services, Los Angeles, CA, USA

Beck, C. T. (2003). Recognizing and Screening for Postpartum Depression in Mothers of NICU Infants. Adv Neonatal Care, Vol. 3, No. 1, (February 2003), pp. 37-46, ISSN 1536-0903

Beck, C. (2008). State of the Science on Postpartum Depression (Parts 1 and 2). MCN: The Amer. J. of Matern \& Child Nurs, Vol. 33, No. 2 \& 3, (March-April 2008 \& May-June 2008), pp. 121-126, 151-156, ISSN 0361-929X

Chaudron, L.H., Szilagyi, P.G., Tang, W., Anson, E., Talbot, N.L., Wadkins, H.I. \& et al. (2010). Accuracy of Depression Screening Tools for Identifying Postpartum Depression among Urban Mothers. Pediatrics, Vol. 125, No. 3, (March 2010), pp. 609-617, ISSN 0031-4005

Cooper, C., Jones, L., Dunn, E., Forty, L., Haque, S. \& Oyebode, F. \& et al. (2007). Clinical Presentation of Postnatal and Non-postnatal Depressive Episodes. Psychol Med, Vol. 37, No. 9, (September 2007), pp. 1273-1280, ISSN 0033-2917

Covey, S. R. (2004). The Seven Habits of Highly Effective People, Free Press, ISBN 978-074-326951-3, New York, NY, USA

Cox, J.L., Holden, J.M. \& Sagovsky, R. (1987). Detection of Postnatal Depression. Development of the 10-item Edinburgh Postnatal Depression Scale. Br J Psychiatry, Vol. 150, (June 1987), pp. 782-786, ISSN 0007-1250 
Cox, J. L., Murray, D. \& Chapman, G. (1993). A Controlled Study of the Onset, Duration and Prevalence of Postnatal Depression. Br J Psychiatry, Vol. 163, No. 1, (July 1993), pp. 27-31, ISSN 0007-1250

Crockett, K., Zlotnick, C., Davis, M., Payne, N. \& Washington, R. (2008). A Depression Preventive Intervention for Rural Low-income African-American Pregnant Women at Risk for Postpartum Depression. Archives of Women's Mental Health, Vol. 11, No. 5-6, (December 2008) pp. 319-325, ISSN 1434-1816

Dillon, W. R. \& Goldstein M. (1984). Multivariate Analysis, John Wiley \& Sons, ISBN 978-0471083-17-7, New York, NY, USA

Dobson, K.S. \& Dozois, D. J. (2008). Risk Factors in Depression, Elsevier Science, ISBN 978-0080450-78-0, Amsterdam, Netherlands

Gaynes, B.N., Gavin, N., Meltzer-Brody, S., Lohr, K.N., Swinson, T., Gartlehner, G., Brody, S. \& Miller W.C. (2005). Perinatal Depression: Prevalence, Screening Accuracy, and Screening Outcomes, Rockville, MD, USA: RTI - International-University of North Carolina Evidence-based Practice Center, Report/Technology Assessment No. 119, Contract No. 290-02-0016

Geronimus, A.T. (1992). The Weathering Hypothesis and the Health of African-American Women and Infants: Evidence and Speculations, Ethn. Dis., Vol. 2, No. 3, (Summer 1992), pp. 207-221, ISSN 1049-510X

Glanz, K., Rimer, B.K. \& Lewis, F.M. (2002). Health Behavior and Health Education. Theory, Research and Practice, Wiley \& Sons, ISBN 978-078-7957-15-5, San Francisco, CA, USA

Hair, J.F., Anderson, R., Tatham R. \& Black, W.C. (1992). Multivariate Data Analysis, 3rd ed, Macmillan, ISBN 978-002-9465-64-6, New York, NY, USA

Jones, J. W. (1989). Personality and Epistemology: Cognitive Social Learning Theory as a Philosophy of Science, Zygon's J of religion \& Science, Vol. 24, No. 1, (March 1989), pp. 23-38, ISSN 0591-2385

Kadane J.B. (1996). Bayesian Methods and Ethics in a Clinical Trial Design, John Wiley \& Sons, ISBN 978-047-1846-80-2, New York, NY, USA

Kozhimannil, K.B., Trinacty, C.M., Busch, A.B., Huskamp, H.A. \& Adams, A.S. (2011). Racial and Ethnic Disparities in Postpartum Depression Care among Lowincome Women, Psychiatric Services, Vol. 62, (June 2011), pp. 619-625, ISSN 1075-2730

Lancaster, C.A., Gold, K.J., Flynn, H.A., Yoo, H., Marcus, S.M. \& Davis, M.M. (2010). Risk Factors for Depressive Symptoms during Pregnancy: a Systematic Review. Am J Obstet Gynecol, Vol. 202, No. 1, (January 2010), pp. 5-14, ISSN 0002-9378

Levinson, D.J. (1996). Seasons of a Woman's Life, Alfred A. Knopf, ISBN 978-034-5311-74-0, New York, NY, USA

Llewellyn, A. M., Stowe, Z.N. \& Nemeroff, C. B. (1997). Depression during Pregnancy and the Puerperium. J Clin Psychiatry, Vol. 58, Suppl, 15, pp. 26-32, ISSN 0160-6689

Luke, S., Salihu, H. M., Alio, A. P., Mbah, A. K., Jeffers, D., Berry, E. \& Mishkit, V. R. (2009). Risk Factors for Major Antenatal Depression among Low-Income African American Women. J of Women's Health, Vol. 18, No. 11, (November 2009), pp. 1841-1846, ISSN 1540-9996 
Morrison, D. F. (1990). Multivariate Statistical Methods, McGraw-Hill, ISBN 978-007-0431-87-4, New York, NY, USA

O'Hara, M. W. \& Swain A. M. (1996). Rates and Risk of Postpartum Depression - a MetaAnalysis. Int Rev Psychiatry, Vol. 8, No. 1, (January 1996), pp. 37-54, ISSN 09540261

O'Hara, M. (1997). The Nature of Postpartum Depressive Disorders, In: Postpartum Depression and Child Development, L. Murray \& P. J. Cooper (Eds.), pp. 3-31, The Guilford Press, 978-157-2301-97-9, New York, NY, USA

Peindl, K.S., Wisner, K.L. \& Hanusa, B.H. (2004). Identifying Depression in the First Postpartum Year: Guidelines for Office-based Screening and Referral. J Affect Disord, Disord, Vol. 80, No. 1, (May 2004), pp. 37-44, ISSN 0165-0327

Pignone, M.P., Gaynes, B.N. \& Rushton, J.L. \& et al. (2002). Screening for Depression in Adults: a Summary of the Evidence for the U.S. Preventive Services Task Force. Ann Intern Med, Vol. 136, No. 10, (May 2002), pp. 765-776, ISSN 0003-4819

Plant, E. A. \& Sachs-Ericsson, N. (2004). Racial and Ethnic Differences in Depression: the Roles of Social Support and Meeting Basic Needs. J of Consulting and Clinical Psychology, Vol. 72, No. 1, (February 2004), pp. 41-52, ISSN 0022-006X

Santrock J.W. (2008). Life-Span Development, McGraw-Hill Humanities Social, ISBN 978-0073310-24-4, New York, NY, USA

Segre, L. S., O'Hara, M. W. \& Losch, M. E. (2006). Race/Ethnicity and Perinatal Depressed Mood. J of Reproductive E Infant Psychology, Vol. 24, No. 2, (May 2006), pp. 99-106, ISSN 0264-6838

Segre, L. S., O'Hara, M. W., Arndt, S. \& Scott Stuart. (2007). The Prevalence of Postpartum Depression: The Relative Significance of Three Social Status Indices. Social Psychiatry and Psychiatric Epidemiology, Vol. 42, No. 4, (April 2007), pp. 316-321, ISSN 0933-7954

Silverman, M. E., Loudon, H., Liu, X., Mauro, C., Leiter, G. \& Goldstein, M. A. (2011). The Neural Processing of Negative Emotion Postpartum: a Preliminary Study of Amygdala Function in Postpartum Depression. Arch Women's Ment Health, Vol. 14, No. 4, (August 2011), pp. 355-359, ISSN 1434-1816

Surkan, P., Peterson, K., Hughes, M. \& Gottlieb, B. (2006). The Role of Social Networks and Support in Postpartum Women's Depression: A Multiethnic Urban Sample. Matern $\mathcal{E}$ Child Health J, Vol. 10, No. 4, (July 2006), pp. 375-383, ISSN 1092-7875

Trevathan, W. (2010). Ancient Bodies, Modern Lives: How Evolution Has Shaped Women's Health. Oxford University Press, ISBN 978-019-5388-88-6, New York, NY, USA

Verinder, S., Vivien, K.B., \& Hendrica, L.R. (2010). Assessment and Treatment of Bipolar II Postpartum Depression: A Review. J Affective Disord., Vol. 125, No. 1, (September 2010), pp. 18-26, ISSN 0165-0327

Wei, G., Greaver, L.B., Marson, S.M., Herndon, C.H. \& Rogers, J. (2008). Postpartum Depression: Racial Differences and Ethnic Disparities in a Tri-racial and Bi-ethnic Population. Matern \& Child Health J, Vol. 12, No. 6, (November 2008), pp. 699-707, ISSN 1092-7875 
Yonkers, K. A., Ramin, S. M., Rush, A. J. \& et al. (2001). Onset and Persistence of Postpartum Depression in an Inner-city Maternal Health Clinic System. Am J Psychiatry, Vol. 158, No. 11, (November 2001), pp. 1856-63, ISSN 0002-953X

Zayas, L. H., Jankowski, K. B. \& McKee, M. D. (2005). Parenting Competency Across Pregnancy and Postpartum Among Urban Minority Women. J of Adult Development, Vol. 12, No. 1, (January 2005), pp. 53-62, ISSN 1068-0667 


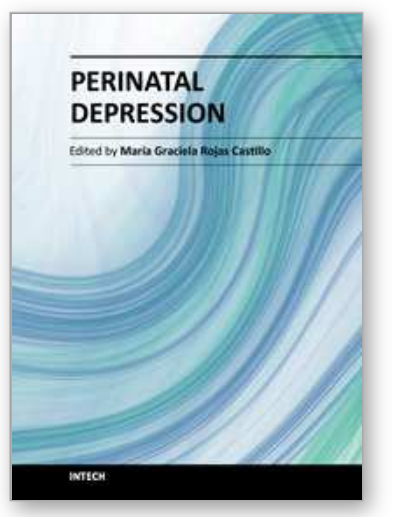

\author{
Perinatal Depression \\ Edited by Dr. María Graciela Rojas Castillo
}

ISBN 978-953-307-826-7

Hard cover, 190 pages

Publisher InTech

Published online 20, January, 2012

Published in print edition January, 2012

This book presents ten chapters that give us important information about epidemiological, biological, clinical and psychological aspects of common mental disorders during pregnancy and in the postnatal period. Some of the issues covered in this book are: detecting postnatal depression using different instruments at the right time, which is very important to avoid the negative effects on the children of depressed mothers; understanding the impact of anxiety and depression during pregnancy and in the postnatal period; biological issues of perinatal anxiety and depression; epidemiological information about perinatal mental health problems among minorities, like immigrant population and underserved rural women. Some information is also provided on postnatal depression in men, which is frequently overlooked.

\title{
How to reference
}

In order to correctly reference this scholarly work, feel free to copy and paste the following:

Guo Wei, Frankie D. Powell, Veronica K. Freeman and Leonard D. Holmes (2012). Perinatal Depression in Minority and Underserved Rural Women, Perinatal Depression, Dr. María Graciela Rojas Castillo (Ed.), ISBN: 978-953-307-826-7, InTech, Available from: http://www.intechopen.com/books/perinatal-depression/perinataldepression-in-minority-and-underserved-rural-women

\section{INTECH}

open science | open minds

\section{InTech Europe}

University Campus STeP Ri Slavka Krautzeka 83/A 51000 Rijeka, Croatia Phone: +385 (51) 770447 Fax: +385 (51) 686166 www.intechopen.com

\author{
InTech China \\ Unit 405, Office Block, Hotel Equatorial Shanghai \\ No.65, Yan An Road (West), Shanghai, 200040, China \\ 中国上海市延安西路65号上海国际贵都大饭店办公楼405单元 \\ Phone: +86-21-62489820 \\ Fax: +86-21-62489821
}


(C) 2012 The Author(s). Licensee IntechOpen. This is an open access article distributed under the terms of the Creative Commons Attribution 3.0 License, which permits unrestricted use, distribution, and reproduction in any medium, provided the original work is properly cited. 